\title{
Effects of inspiratory muscle training on dynamic hyperinflation in patients with COPD
}

This article was published in the following Dove Press journal:

International Journal of COPD

29 November 2012

Number of times this article has been viewed

\section{Milos Petrovic' \\ Michael Reiter ${ }^{2}$ \\ Harald Zipko ${ }^{3}$ \\ Wolfgang Pohl' \\ Theodor Wanke'}

'Pulmonary Department and Karl Landsteiner Institute for Clinical and Experimental Pulmology, Hietzing Hospital, Vienna, Austria; ${ }^{2}$ Department of Respiratory and Critical Care Medicine, Otto Wagner Hospital, Vienna, Austria; ${ }^{3} \mathrm{FH}$ Campus Vienna, University of Applied Sciences Health Department, Vienna, Austria
Correspondence: Milos Petrovic Pulmonary Department and Karl Landsteiner Institute for Clinical and Experimental Pulmology, Hietzing Hospital, Wolkensbergenstrasse I, II 30 Vienna, Austria

Tel +436648445331

Fax $+43 \quad 180 \quad 1102476$

Email milos.petrovic@wienkav.at
Abstract: Dynamic hyperinflation has important clinical consequences in patients with chronic obstructive pulmonary disease (COPD). Given that most of these patients have respiratory and peripheral muscle weakness, dyspnea and functional exercise capacity may improve as a result of inspiratory muscle training (IMT). The aim of the study was to analyze the effects of IMT on exercise capacity, dyspnea, and inspiratory fraction (IF) during exercise in patients with COPD. Daily inspiratory muscle strength and endurance training was performed for 8 weeks in 10 patients with COPD GOLD II and III. Ten patients with COPD II and III served as a control group. Maximal inspiratory pressure (Pimax) and endurance time during resistive breathing maneuvers (tlim) served as parameter for inspiratory muscle capacity. Before and after training, the patients performed an incremental symptom limited exercise test to maximum and a constant load test on a cycle ergometer at $75 \%$ of the peak work rate obtained in the pretraining incremental test. ET was defined as the duration of loaded pedaling. Following IMT, there was a statistically significant increase in inspiratory muscle performance of the Pimax from $7.75 \pm 0.47$ to $9.15 \pm 0.73 \mathrm{kPa}(P<0.01)$ and of tim from $348 \pm 54$ to $467 \pm 58$ seconds $(P<0.01)$. A significant increase in IF, indicating decreased dynamic hyperinflation, was observed during both exercise tests. Further, the ratio of breathing frequency to minute ventilation (bf $/ \mathrm{V}_{\mathrm{E}}^{\prime}$ ) decreased significantly, indicating an improved breathing pattern. A significant decrease in perception of dyspnea was also measured. Peak work rate during the incremental cycle ergometer test remained constant, while ET during the constant load test increased significantly from $597.1 \pm 80.8$ seconds at baseline to $733.6 \pm 74.3$ seconds $(P<0.01)$. No significant changes during either exercise tests were measured in the control group. The present study found that in patients with COPD, IMT results in improvement in performance, exercise capacity, sensation of dyspnea, and improvement in the IF prognostic factor.

Keywords: chronic obstructive pulmonary disease, cycle ergometer test, dynamic hyperinflation, dyspnea, inspiratory muscle training

\section{Introduction}

Chronic obstructive pulmonary disease (COPD) is a common disease that can substantially impair one's quality of life and increase the risk of premature death.

It is a progressive disorder characterized by a partially reversible expiratory airflow limitation. The pathological hallmarks of COPD are inflammation of the peripheral airways and destruction of lung parenchyma or emphysema. It encompasses both emphysema and chronic bronchitis. The airflow limitation is usually progressive and is associated with an abnormal inflammatory response of the lungs to inhaled noxious particles or gases. 
Expiratory airflow limitation and loss of the lung's elastic recoil promotes air trapping with an increase in endexpiratory lung volume (EELV), a decrease in inspiratory capacity (IC), and lung hyperinflation. Consistent reduction in IC during physical activities reflects dynamic hyperinflation. Dynamic hyperinflation appears to be the main cause of exertional breathlessness and exercise performance in patients with COPD. ${ }^{1}$

Inspiratory muscle training (IMT) is known to be "an adjunctive therapy in pulmonary rehabilitation, primarily in patients with suspected or proven respiratory muscle weakness."2 IMT positively influences exercise capacity in $\mathrm{COPD},{ }^{3}$ but its effects on dynamic hyperinflation are still controversial.

We examined the benefits of a short outpatient program of IMT on inspiratory muscle performance, exercise capacity, perception of dyspnea, and inspiratory fraction ([IF] = IC/ total lung capacity [TLC]). The objective of this study was to analyze the effects of IMT on IF during exercise, exercise capacity, and sensation of dyspnea in patients with COPD.

\section{Materials and methods Subjects}

Twenty subjects with moderate to severe COPD GOLD II and III were recruited from our outpatient clinic for the study. According to the criteria of the American Thoracic Society (ATS), ${ }^{4}$ COPD is defined as postbronchodilator forced expiratory volume in 1 second $\left(\mathrm{FEV}_{1}\right)$ of $30 \%$ to $79 \%$ of the predicted value and a ratio of $\mathrm{FEV}_{1}$ to forced vital capacity (FVC) $<70 \%$.

Ten subjects (6 male and 4 female) underwent IMT, while the other ten patients ( 5 male and 5 female) served as a control group. The baseline characteristics of the patients are summarized in Table 1. There were no significant differences in anthropometric data, lung function parameters, and exercise capacity between groups.

All patients were initially observed over a 4-week observation period while their regular treatment was maintained. During this period, no patients experienced symptoms of respiratory infection. Inclusion criteria required subjects to be less than 70 years old and to have moderate to severe nonreversible airflow obstruction. Exclusion criteria were the exacerbation of COPD within the previous 6 weeks, neoplastic disease or the presence of a disease that could contribute to dyspnea, or exercise limitation (cardiovascular, neuromuscular, or other respiratory diseases). No patients had received treatment with systemic cortisone over the last 6 months.
Table I Baseline characteristics of the patients

\begin{tabular}{lll}
\hline Parameter & Control group & Training group \\
\hline Subjects $(\mathrm{n})$ & 10 & 10 \\
Male/female & $5 / 5$ & $6 / 4$ \\
Age (years) & $60.3 \pm 5.3$ & $58.7 \pm 5.2$ \\
Height $(\mathrm{cm})$ & $171.0 \pm 6.0$ & $171.0 \pm 7.6$ \\
Weight $(\mathrm{kg})$ & $71.3 \pm 13.9$ & $71.4 \pm 17.4$ \\
$\mathrm{BMI}\left(\mathrm{kg} \cdot \mathrm{m}^{-2}\right)$ & $24.2 \pm 3.4$ & $24.3 \pm 4.0$ \\
Lung function parameters & & \\
FEV $(\mathrm{L})$ & $1.85 \pm 0.37$ & $1.97 \pm 0.38$ \\
$\mathrm{FEV},(\%)$ & $54.80 \pm 8.17$ & $55.90 \pm 6.70$ \\
FVC $(\mathrm{L})$ & $3.47 \pm 0.40$ & $3.62 \pm 0.69$ \\
$\mathrm{RV}(\mathrm{L})$ & $2.59 \pm 0.63$ & $2.69 \pm 0.64$ \\
$\mathrm{FEV}, \mathrm{FVC}(\%)$ & $58.5 \pm 6.9$ & $60.2 \pm 5.6$ \\
$\quad \mathrm{TLC}$ & $7.120 \pm 0.434$ & $7.025 \pm 1.267$ \\
IC & $3.039 \pm 0.203$ & $3.107 \pm 1.106$ \\
Exercise performance & & \\
$\quad$ Work rate in watts (min/max) & $105 \pm 28$ & $109 \pm 43$ \\
\hline
\end{tabular}

Note: Data are presented as mean \pm I SD.

Abbreviations: BMI, body mass index; $\mathrm{FEV}_{\text {, }}$, forced expiratory volume in I second; FVC, forced vital capacity; IC, inspiratory capacity; RV, residual volume; TLC, total lung capacity.

\section{Study design}

The effects of IMT were investigated by using a randomized controlled study. All measurements were performed before the IMT and within 1 week after its completion. After familiarization with testing procedures, subjects underwent pulmonary function testing. Pulmonary function testing is a symptom-limited incremental test that defines the peak work rate according to ATS standards. ${ }^{5}$ A constant work test at $75 \%$ of peak work rate taken was performed the following day. Ten subjects received specific inspiratory muscle training on a daily basis for 8 weeks, with the other ten patients serving as a control group.

All subjects provided their written consent for the study, which was approved by the Vienna Health Authority research ethics committee.

\section{Baseline pulmonary function test}

In order to confirm diagnosis and determine severity of the disease, standard forced expiratory spirometry $\left(\mathrm{FEV}_{1}\right.$ and FVC) and body plethysmography (residual volume, functional residual capacity, TLC) were evaluated in both groups, according to $\mathrm{ATS}^{4}$ before and after IMT using a computerized spirometer (Masterlab; Jaeger, Wuerzburg, Germany).

Incremental cycle ergometer testing and constant load cycle ergometer testing

At the start and the end of the study, all patients performed a symptom-limited incremental exercise test on the Ergoline 
800 electronically braked cycle ergometer (Ergoline, Bitz, Germany). Incremental exercise tests consisted of a steady state resting period of 3 minutes followed by stepwise protocol increases of 20-30 watts every 2 minutes depending on the baseline fitness of the participant. The test ended at the point of peak exercise, which is defined as an inability to maintain the load reached. A constant load test on the electronically braked cycle ergometer was set at $75 \%$ of the peak work rate obtained in the pre-training incremental test.

During these tests, gas exchange, ventilatory parameters, and heart rate were recorded breath by breath (Oxycon Pro; Jaeger). Constant load test endurance time (ET) was defined as the duration of loaded pedaling. IC and IF were measured every second minute during both ergometer exercise tests and also served as parameter for dynamic hyperinflation. It is assumed that TLC remains constant during exercise in COPD. ${ }^{6}$

In order to reach satisfactory reproducibility of IC maneuvers, patients were given a few breath warnings before the maneuver started. Subjects were instructed to breathe in until their lungs were full and then asked to try to fill up even more (ie, to inspire to TLC) before returning to normal breathing. If efforts appeared submaximal, then IC was not accepted.

The sensation of dyspnea during exercise was measured every 2 minutes using the Borg Category Ratio scale. Measurements of IC, BORG dyspnea ratings, and ET during cycle exercise testing are known to be highly reproducible and responsive to change in patients with COPD. ${ }^{8}$

\section{Inspiratory muscle training}

Subjects were instructed to perform IMT sessions once per day, 7 days per week, for 8 weeks. Daily training sessions started with strength training and were followed by endurance training 15 minutes later. Patients had to perform the training seated and using a nose clip.

Daily inspiratory muscle strength and endurance training were performed using the same training device (Respifit $\mathrm{S}^{\mathrm{TM}}$; Mauerbach, Austria). ${ }^{9}$ Maximal inspiratory pressure (Pimax) and ET during resistive breathing maneuvers (tlim) served as parameters for inspiratory muscle capacity. Pimax is a reliable, noninvasive parameter for assessing the respiratory muscle strength.

\section{Strength exercises}

Patients performed ten inspiratory maneuvers against closeto-maximum resistance and had to reach at least $80 \%$ of Pimax for a minimum of 1 second in order to complete the strength training. This subjects the respiratory muscles, and the diaphragm in particular, to maximum strain. The strength exercise involves the constriction of the air duct allowing only for a minimal amount of air to be inhaled. Each inspiratory maneuver starts from the point of maximum expiration (residual volume).

Each training (block of exercises) included ten individual exercises. If all individual exercises were completed successfully, the training was considered a success and was stored as such on the chipcard.

The length of the break between each individual exercise was 10 seconds. If the specified minimum pressure was not reached twice during the training session, training was terminated and stored as unsuccessful on the patient's chipcard. Training intensity was increased every 2 weeks by reevaluating Pimax. Fifteen efforts were performed at level functional residual capacity to determine Pimax and the highest value was used.

\section{Endurance exercises}

The exercise was performed by breathing against a predefined level of resistance. tlim, a parameter of respiratory muscle endurance, is defined as the time until the onset of muscle exhaustion of the respiratory pump (muscle fatigue) during resistive breathing against a predefined inspiratory load.

During the exercise, the patients breathed at normal breathing frequency until the specified target value could not be achieved for four subsequent breaths (sign of muscle exhaustion). The subjects had to achieve a target pressure of $60 \%$ of the previously determined Pimax value. The elapsed time in seconds from the beginning of the exercise until the onset of muscle exhaustion was determined as tlim.

Inspiratory muscle endurance training consisted of ten loaded breathing cycles against a variable flow-dependent inspiratory resistance of 1-minute duration each, separated by 20 -second intervals. The intensity of endurance training was also increased every 2 weeks.

A graphical display on the training device gave visual feedback on training results to indicate whether the strength or endurance training was completed successfully. The number of correctly and incorrectly performed exercises was saved on individual memory cards, enabling the physician to check each patient's training.

\section{Statistical analysis}

Results of the baseline and descriptive statistical analysis in tables are expressed as mean \pm 1 standard deviation (SD) 
or median $\pm 95 \%$ confidence interval (CI). Values shown in figures are described as mean \pm 1 standard error of the mean $(\mathrm{SEM})$ or median $\pm 95 \%$ CI. The Shapiro-Wilk test was used for preliminary testing to evaluate if grouped data were normally distributed $(P<0.05)$. Based on general linear models, univariate analysis of variance with repeated measures (Greenhouse-Geisser correction) was used to compare the effects of IMT on: (1) inspiratory muscle capacity (Pimax, tlim); (2) incremental exercise capacity (IF, $\mathrm{V}^{\prime} \mathrm{O}_{2}, \mathrm{bf} / \mathrm{V}_{\mathrm{E}}^{\prime}$ ); (3) constant work rate $\left(\mathrm{ET}, \mathrm{bf} / \mathrm{V}_{\mathrm{E}}^{\prime}\right)$; and (4) sensation of dyspnea (BORG Scale). Analysis of variance results between groups and between subjects (both with Bonferroni correction for pairwise comparisons) and interactions with values of $P<0.05$ were considered significant. Statistical analysis and graphs were generated using the SPSS (v 17; IBM Corporation, Armonk, NY), Excel 2007 (Microsoft Corporation, Redmond, WA), and $\mathrm{R}$ (v 2.10.1; R Foundation for Statistical Computing, Vienna, Austria) software programs. ${ }^{10}$

\section{Results}

\section{Effects of IMT on inspiratory muscle capacity}

The training group showed a significant increase of inspiratory muscle performance following 8 weeks of daily IMT. Pimax increased by $18 \%$ (from $7.75 \pm 0.47 \mathrm{kPa}$ to $9.15 \pm 0.73 \mathrm{kPa}$, respectively; $P<0.001)$. ET during tlim increased from $348 \pm 54$ seconds to $467 \pm 58$ seconds, which means an increase of $34 \%(P<0.001$; Table 2$)$.

In contrast, these parameters remained unchanged in the control group.

\section{Effects of IMT on incremental exercise capacity}

Following the training period, there was a statistically significant increase of IC (from $2.98 \pm 0.77$ to $3.31 \pm 0.89$, $P<0.001)$ during the incremental cycle ergometer test and therefore an increase of IF, which increased by $9.8 \%$ (from $0.41 \pm 0.05$ to $0.45 \pm 0.05, P<0.001)$, indicating decreased dynamic hyperinflation (Figure 1; Table 3).
Exercise performance was assessed by evaluating $\mathrm{VO}_{2}$ max and was also higher after training (increase of $2 \%$ from $1887.6 \pm 263.1 \mathrm{~mL}$ to $1925.0 \pm 244.3 \mathrm{~mL}$ ). The peak work rate (watt max) remained constant.

The ratio of breathing frequency to minute ventilation (bf $/ \mathrm{V}_{\mathrm{E}}^{\prime}$ ) showed a significant decrease from $0.48 \pm 0.11$ to $0.46 \pm 0.13$ ( $P<0.001$; Figure 2; Table 3). Mean inspiratory flow increased from $2.19 \pm 0.32$ to $2.30 \pm 0.31(P<0.001$; Figure 3; Table 3). The level of dyspnea (BORG Scale) also showed a significant decrease (from $5.0 \pm 1.0$ to $4.0 \pm 1.1$; $P<0.01$; Table 3).

The difference between the training group and the control group was significant for IC $(P<0.032)$, IF $(P<0.001)$, and $\mathrm{bf} / \mathrm{V}_{\mathrm{E}}^{\prime}(P<0.001)$ after the 8 -week observation period. No changes occurred in the control group.

\section{Effects of IMT on constant work rate}

ET during the constant load test on a cycle ergometer increased significantly from $597.1 \pm 80.8$ seconds at baseline to $733.6 \pm 74.3$ seconds in the training group, which is an improvement of $22.9 \%(P<0.001$; Table 3$)$.

$\mathrm{bf} / \mathrm{V}_{\mathrm{E}}^{\prime}$ significantly improved, decreasing from $0.5 \pm 0.11$ to $0.48 \pm 0.11$ in the training group $(P<0.001$; Figure 4 ; Table 3 ) and mean inspiratory flow increase from $2.16 \pm 0.31$ to $2.31 \pm 0.30(P<0.001$; Figure 5; Table 3$)$.

IF showed a significant increase, from $0.43 \pm 0.03$ to $0.44 \pm 0.03(P<0.001$; Figure 6; Table 3$)$, and sensation of dyspnea was significantly lower, decreasing from $7.0 \pm 0.7$ to $5.0 \pm 0.9(P<0.001$; Table 3$)$.

After the 8-week observation period, differences between the training and control groups were significant for IC $(P<0.001)$, IF $(P<0.001)$, and bf $/ \mathrm{V}_{\mathrm{E}}^{\prime}(P<0.018)$.

The control group showed no significant change in ET, breathing pattern, BORG Scale, or dynamic hyperinflation.

\section{Discussion}

Both inspiratory muscle capacity and peripheral muscle force are negatively affected in patients with COPD. Skeletal muscle weakness is known to contribute to exercise

Table 2 Respiratory muscle function parameters at the beginning and end of observation

\begin{tabular}{|c|c|c|c|c|c|c|c|}
\hline \multirow[t]{2}{*}{ Test } & \multicolumn{2}{|c|}{ Control group } & \multicolumn{2}{|c|}{ Training group } & \multicolumn{3}{|c|}{ ANOVA } \\
\hline & Baseline & Week 8 & Baseline & Week 8 & $P^{a}$ & $P^{b}$ & $P^{c}$ \\
\hline$t \lim (s)$ & $287.3 \pm 48.1$ & $254.0 \pm 43.2$ & $348.4 \pm 54.4$ & $467.4 \pm 58.3$ & $<0.001$ & $<0.001$ & $<0.001$ \\
\hline Pimax (kPa) & $7.91 \pm 0.67$ & $7.57 \pm 0.73$ & $7.75 \pm 0.47$ & $9.15 \pm 0.73$ & $<0.001$ & 0.023 & $<0.001$ \\
\hline
\end{tabular}

Notes: Data are presented as mean \pm I SD unless otherwise stated. Pa: results of analysis of variance (ANOVA) comparison of control group versus training group with repeated measurements (within-subject effects); $P^{b}$ : results of ANOVA comparison of control versus training group (between-group effects); $P^{c}$ : results of ANOVA comparison of baseline versus week 8 with repeated measurements (within-subject effects).

Abbreviations: ANOVA, analysis of variance; Pimax, maximal inspiratory pressure; tlim, resistive breathing maneuvers. 


\section{A Time course of changes in IF during incremental load excercise}

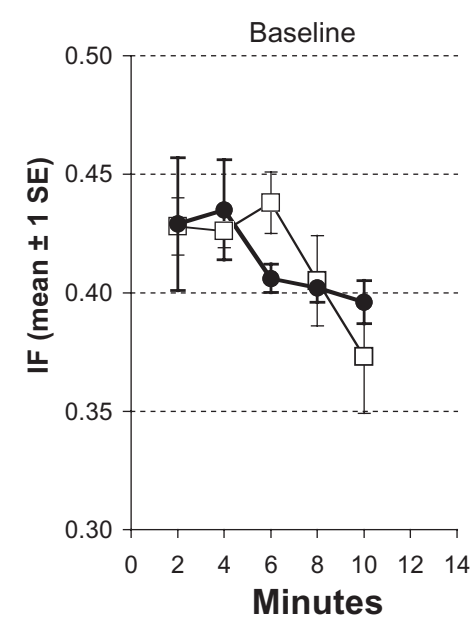

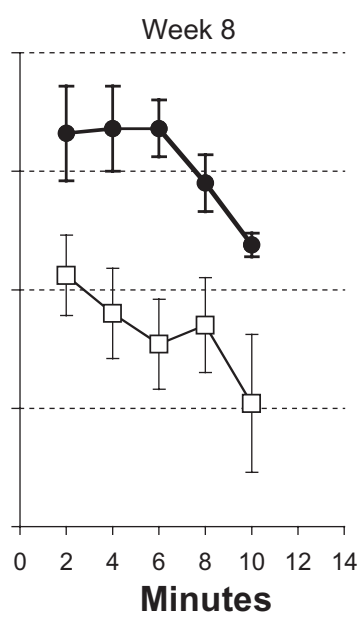

\section{B ANOVA interactions}

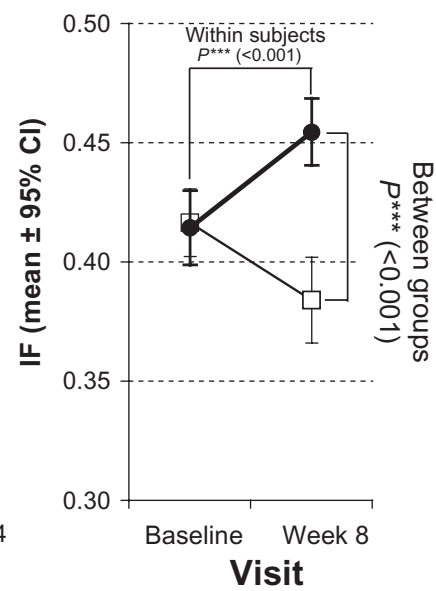

Figure I Measurements of inspiratory capacity (IF) during incremental load test. Solid symbols $\bullet$ : subjects with inspiratory muscle training; open symbols $\square$ : control group. (A) Time courses of changes at baseline and after 8 weeks. Values represented as stepwise means \pm I standard error (SE) of the mean every 2 min; (B) results of analysis of variance (ANOVA) (repeated measurement design) representing interactions of within-subject and between-group effects.

Note: Values represented as mean $\pm 95 \%$ confidence interval $(\mathrm{Cl})$.

limitation. ${ }^{11,12}$ Respiratory muscle training has been shown to positively influence the sensations of dyspnea, exercise tolerance, and quality of life, ${ }^{13}$ but the exact mechanisms remain unclear.

The efficiency of IMT is known to be influenced by training strategy and patient characteristics. ${ }^{14}$ The most effective method for training the inspiratory muscles has yet to be defined.
The training device used was equipped with a visual feedback system allowing the patients to control the success of the training. This proved to be important in motivating the patients, as IMT is considered to be cumbersome, boring, and without immediate effects. In addition, this feedback system enables the patient to breathe with a constant inspiratory flow during tlim. Our training protocol contained both strength and endurance components. The endurance training

Table 3 Comparison of spirometric data at the beginning and end of observation

\begin{tabular}{|c|c|c|c|c|c|c|c|}
\hline \multirow[t]{2}{*}{ Test } & \multicolumn{2}{|l|}{ Control group } & \multicolumn{2}{|l|}{ Training group } & \multicolumn{3}{|c|}{ ANOVA } \\
\hline & Baseline & Week 8 & Baseline & Week 8 & $P^{a}$ & $P^{\mathrm{b}}$ & $P^{c}$ \\
\hline \multicolumn{8}{|l|}{ Constant load test } \\
\hline IC & $2.95 \pm 0.42$ & $2.46 \pm 0.4 I$ & $3.06 \pm 0.47$ & $3.11 \pm 0.58$ & $<0.001$ & $<0.001$ & $<0.001$ \\
\hline IF (IC/TLC) & $0.41 \pm 0.05$ & $0.34 \pm 0.05$ & $0.43 \pm 0.03$ & $0.44 \pm 0.03$ & $<0.001$ & $<0.001$ & $<0.001$ \\
\hline $\mathrm{bf} / \mathrm{V}_{\mathrm{E}}^{\prime}$ & $0.52 \pm 0.09$ & $0.54 \pm 0.09$ & $0.50 \pm 0.11$ & $0.48 \pm 0.11$ & $<0.001$ & 0.018 & 0.649 \\
\hline $\mathrm{Vt} / \mathrm{ti}(\mathrm{L} / \mathrm{sec})$ & $2.22 \pm 0.27$ & $2.19 \pm 0.27$ & $2.16 \pm 0.31$ & $2.31 \pm 0.30$ & $<0.001$ & 0.184 & $<0.001$ \\
\hline $\mathrm{V}^{\prime} \mathrm{O}_{2}\left(\mathrm{~mL} \cdot \mathrm{min}^{-1}\right)$ & $1644.8 \pm 208.9$ & $1617.6 \pm 190.1$ & $1779.7 \pm 268.8$ & $1805.3 \pm 276.8$ & $<0.001$ & 0.148 & 0.901 \\
\hline BORG $( \pm 95 \% \mathrm{Cl})$ & $4.0 \pm 0.9$ & $6.0 \pm 1.0$ & $7.0 \pm 0.7$ & $5.0 \pm 0.9$ & $<0.001$ & 0.215 & 0.124 \\
\hline $\mathrm{ET}(\mathrm{s})$ & $606.0 \pm 126.4$ & $573.4 \pm 118.5$ & $597.1 \pm 80.8$ & $733.6 \pm 74.3$ & $<0.001$ & 0.100 & 0.002 \\
\hline \multicolumn{8}{|l|}{ Incremental load test } \\
\hline IC & $2.98 \pm 0.35$ & $2.74 \pm 0.44$ & $2.98 \pm 0.77$ & $3.31 \pm 0.89$ & $<0.001$ & 0.032 & 0.125 \\
\hline IF (IC/TLC) & $0.42 \pm 0.05$ & $0.38 \pm 0.06$ & $0.41 \pm 0.05$ & $0.45 \pm 0.05$ & $<0.001$ & 0.001 & 0.268 \\
\hline $\mathrm{bf} / \mathrm{V}_{\mathrm{E}}^{\prime}$ & $0.57 \pm 0.14$ & $0.59 \pm 0.14$ & $0.48 \pm 0.11$ & $0.46 \pm 0.13$ & $<0.001$ & $<0.001$ & 0.780 \\
\hline $\mathrm{Vt} / \mathrm{ti}(\mathrm{l} / \mathrm{s})$ & $2.21 \pm 0.33$ & $2.20 \pm 0.33$ & $2.19 \pm 0.32$ & $2.30 \pm 0.31$ & $<0.001$ & 0.675 & $<0.001$ \\
\hline $\mathrm{V}^{\prime} \mathrm{O}_{2}\left(\mathrm{~mL} \cdot \mathrm{min}^{-1}\right)$ & $1753.6 \pm 226.2$ & $1712.9 \pm 209.1$ & $1887.6 \pm 263.1$ & $1925.0 \pm 244.3$ & $<0.001$ & 0.118 & 0.845 \\
\hline BORG $( \pm 95 \% \mathrm{Cl})$ & $4.0 \pm 0.9$ & $5.0 \pm 1.2$ & $5.0 \pm 1.0$ & $4.0 \pm 1.1$ & $<0.001$ & 0.738 & 0.282 \\
\hline
\end{tabular}

Notes: Data are presented as mean \pm I SD unless otherwise stated. Pa: results of analysis of variance (ANOVA) comparison of control group versus training group with repeated measurements (within-subject effects); $P^{\mathrm{b}}$ : results of ANOVA comparison of control versus training group (between-group effects); $P^{c}$ : results of ANOVA comparison of baseline versus week 8 with repeated measurements (within-subject effects).

Abbreviations: bf, breathing frequency; BORG, Borg Category Ratio scale (I-I0); Cl, confidence interval; ET, endurance time; IC, inspiratory capacity; IF, insipratory fraction; TLC, total lung capacity; tlim, $\mathrm{V}_{\mathrm{E}}^{\prime}$, minute ventilation; $\mathrm{V}^{\prime} \mathrm{O}_{2}$, peak oxygen uptake; $\mathrm{Vt} / \mathrm{ti}$, mean inspiratory flow. 


\section{A Time course of changes in bf/V'E during incremental load excercise}
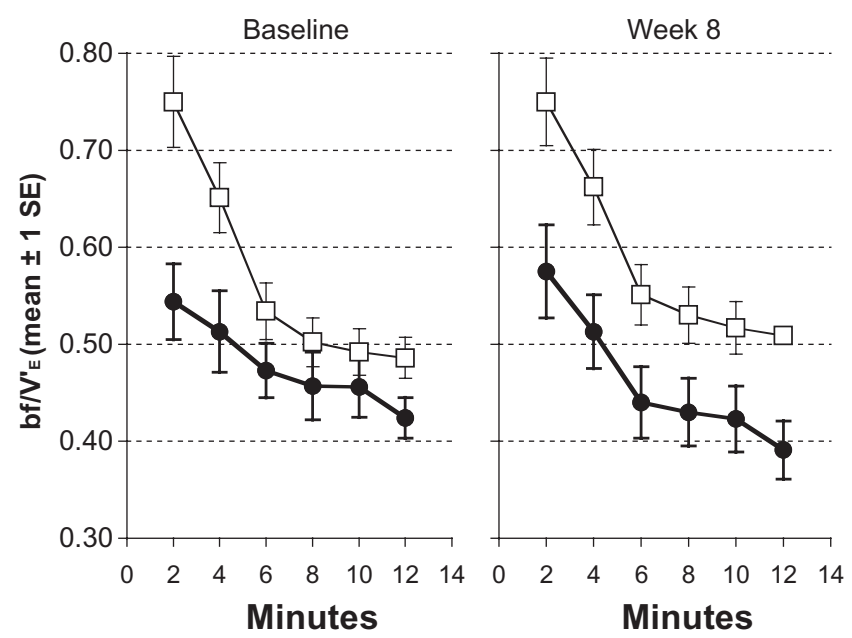

\section{B ANOVA interactions}

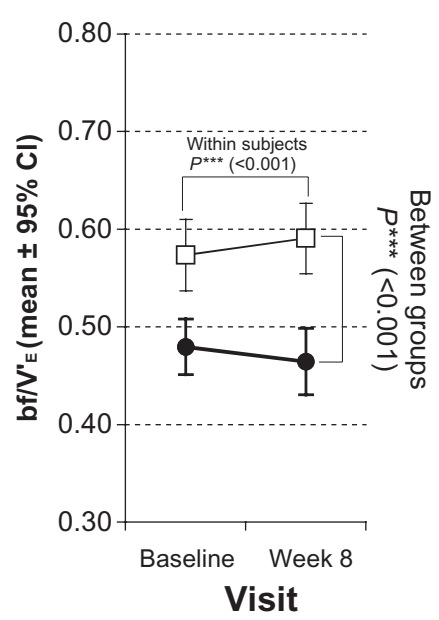

Figure 2 Measurements of breathing frequency (bf/ $\mathrm{V}_{\mathrm{E}}^{\prime}$ ) during incremental load test. Solid symbols $\bullet$ : subjects with inspiratory muscle training; open symbols $\square$ : control group. (A) Time courses of changes at baseline and after 8 weeks. Values represented as stepwise means \pm I standard error (SE) of the mean every 2 min; (B) results of analysis of variance (ANOVA) (repeated measurement design) representing interactions of within-subject and between-group effects.

Notes: Values represented as mean $\pm 95 \%$ confidence interval $(\mathrm{Cl})$.

was performed with at least $60 \%$ of Pimax because training with low pressures has been shown not to improve inspiratory muscle function. ${ }^{15}$

Dynamic hyperinflation appears to be the main cause of exertional breathlessness and exercise performance in patients with COPD. Hyperinflation causes profound dyspnea and activity limitations, which have very significant long term consequences. ${ }^{16}$ The primary goal for treatment of
COPD patients should therefore be the deflation of the lungs, thus achieving a greater inspiratory capacity and relieving shortness of breath.

Pharmacological therapy such as long-acting bronchodilators has been documented to improve dynamic small airway function, leading to lung deflation and overall improvement in exercise performance. ${ }^{17,18}$ In addition, a number of non-pharmacological therapies can also reduce dynamic

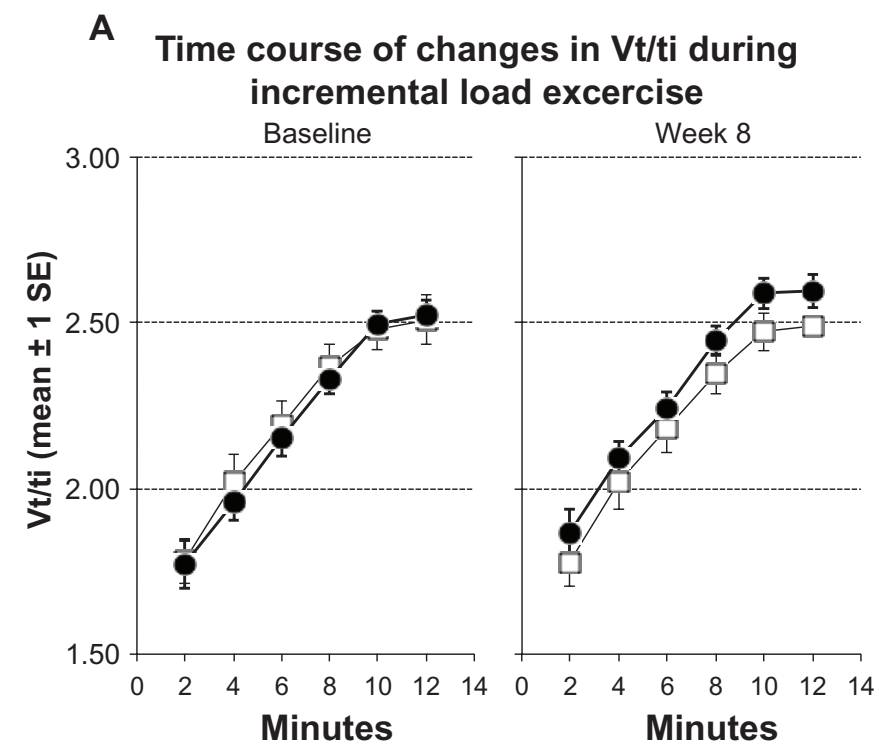

B
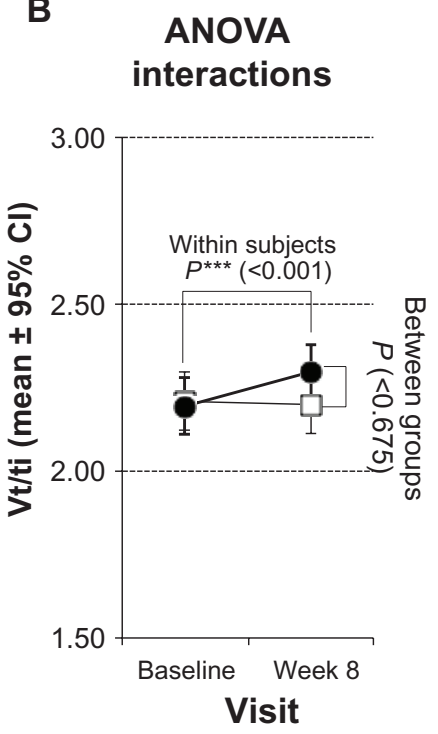

Figure 3 Measurements of mean inspiratory flow (Vt/ti) during incremental load test. Solid symbols $\bullet$ : subjects with inspiratory muscle training; open symbols $\square$ : control group. (A) Time courses of changes at baseline and after 8 weeks. Values represented as stepwise means \pm I standard error (SE) of the mean every 2 min; (B) results of analysis of variance (ANOVA) (repeated measurement design) representing interactions of within-subject and between-group effects.

Note: Values represented as mean $\pm 95 \%$ confidence interval $(\mathrm{Cl})$. 
A

Time course of changes in bf/V'E during constant load excercise

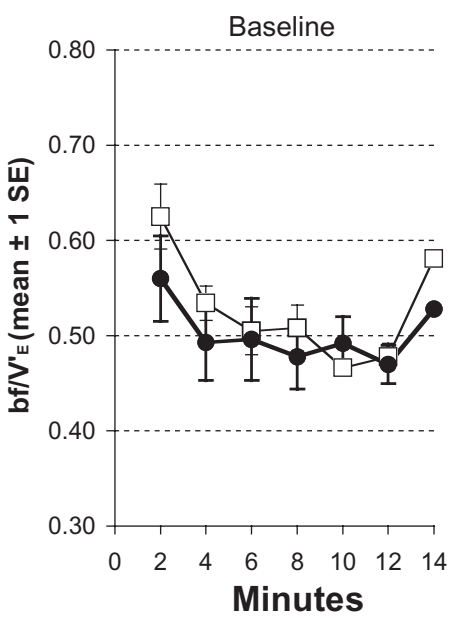

Week 8

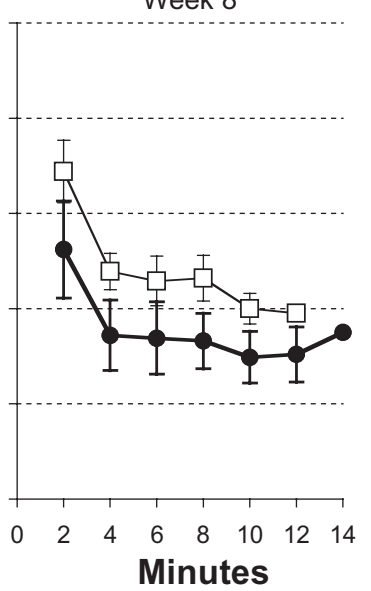

B

\section{ANOVA interactions}

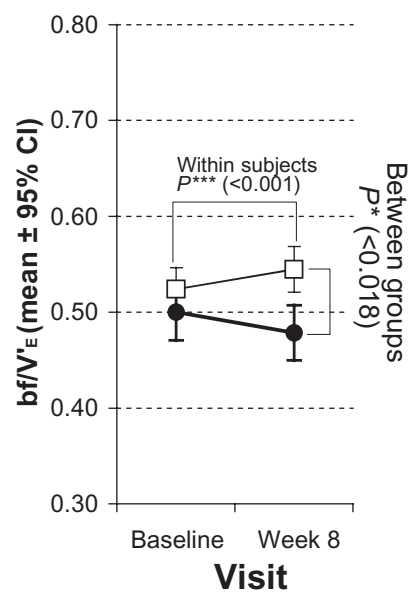

Figure 4 Measurements of breathing frequency (bf/ $\mathrm{V}_{\mathrm{E}}^{\prime}$ ) during constant load test. Solid symbols $\bullet$ : subjects with inspiratory muscle training; open symbols $\square$ : control group. (A) Time courses of changes at baseline and after 8 weeks. Values represented as stepwise means \pm I standard error (SE) of the mean every 2 min; (B) results of analysis of variance (ANOVA) (repeated measurement design) representing interactions of within-subject and between-group effects.

Note: Values represented as mean $\pm 95 \%$ confidence interval $(\mathrm{Cl})$.

hyperinflation such as oxygen therapy, ${ }^{19}$ heliox, ${ }^{20,21}$ lung volume reduction surgery, ${ }^{22,23}$ and general exercise training. ${ }^{24}$

The most important finding of our study is the observed increase in exercise capacity and the significant reduction in dynamic hyperinflation, as reflected by the significant increase in IF. This is the first study showing positive effects of IMT on dynamic hyperinflation in patients with COPD. Therefore, apart from the aforementioned pharmacological and non-pharmacological treatment modalities, IMT can be seen as an additional therapy modality to reduce dynamic hyperinflation.

IF can predict mortality in patients with $\mathrm{COPD}^{25}$ and we hypothesized that IMT positively influences the survival rate of COPD patients. One mechanism for the reduced dynamic hyperinflation induced by IMT may be the optimization of breathing patterns during exercise.

\section{A}

Time course of changes in Vt/ti during constant load excercise
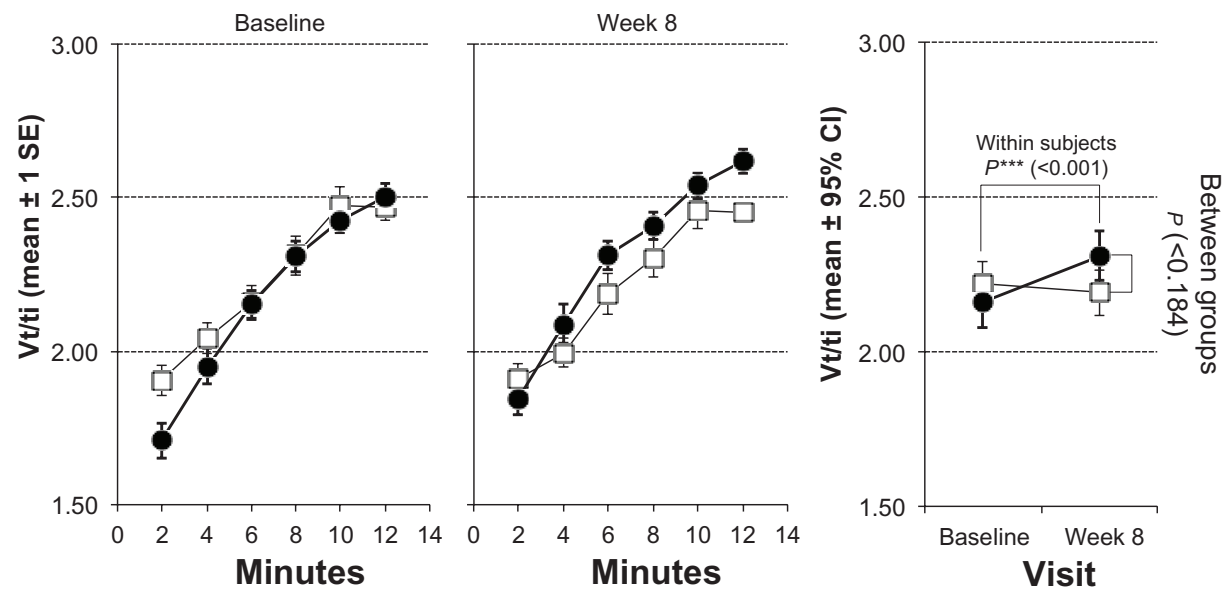

Figure 5 Measurements of mean inspiratory flow (Vt/ti) during constant load test. Solid symbols $\bullet$ : subjects with inspiratory muscle training; open symbols $\square$ : control group. (A) Time courses of changes at baseline and after 8 weeks. Values represented as stepwise means \pm I standard error (SE) of the mean every 2 min; (B) results of analysis of variance (ANOVA) (repeated measurement design) representing interactions of within-subject and between-group effects.

Note: Values represented as mean $\pm 95 \%$ confidence interval $(\mathrm{Cl})$. 


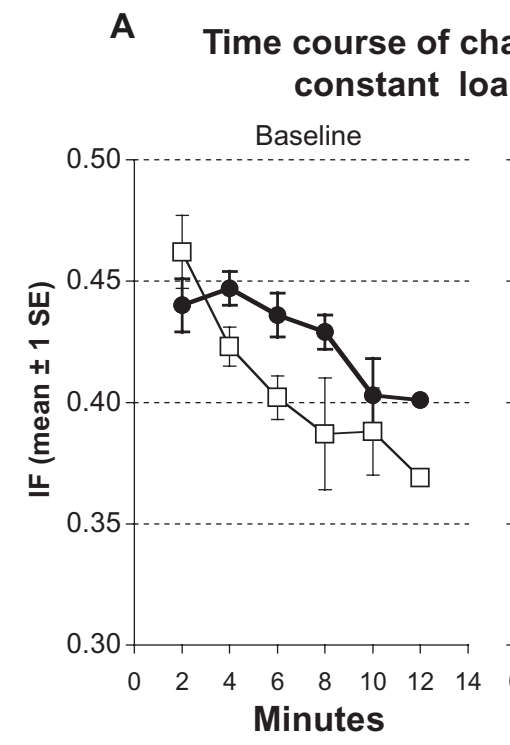

\section{hanges in IF during}

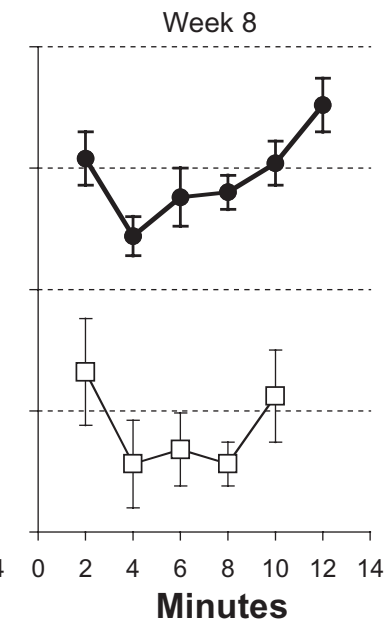

B

\section{ANOVA interactions}

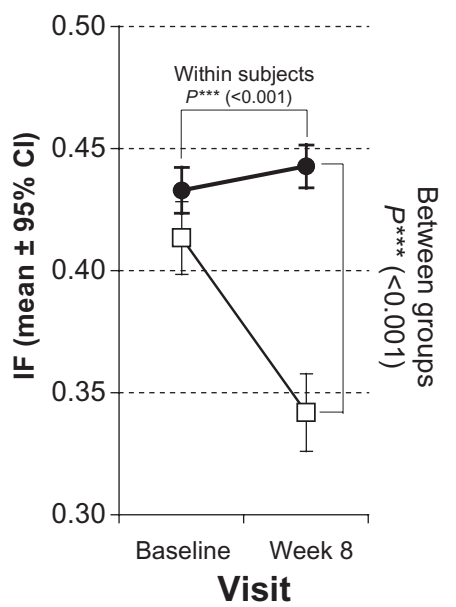

Figure 6 Measurements of inspiratory fraction (IF) during constant load test. Solid symbols $\bullet$ : subjects with inspiratory muscle training; open symbols $\square$ : control group. (A) Time courses of changes at baseline and after 8 weeks. Values represented as stepwise means \pm I standard error (SE) of the mean every 2 min; (B) results of analysis of variance (ANOVA) (repeated measurement design) representing interactions of within-subject and between-group effects.

Note: Values represented as mean $\pm 95 \%$ confidence interval $(\mathrm{Cl})$.

Significant increase in the size of type 2 muscle fiber following IMT in patients with COPD were observed, ${ }^{26}$ and enhancement of velocity of inspiratory muscle shortening 27 was demonstrated. We hypothesize that IMT shortens inspiratory time. This allows more time for exhalation and relaxation and may reduce dynamic hyperinflation, facilitating lung emptying. This study showed that increased muscle capacity led to improvements in breathing patterns, with a significant decrease of the fraction breathing frequency (bf) to minute ventilation (Ve) and an increase of mean inspiratory flow both during incremental and constant load exercises. This pattern of breathing, in conjunction with greater respiratory muscle strength and endurance, seems to be the most important reason for the observed reduction in breathlessness during both kinds of exercise tests.

In conclusion, inspiratory muscle strength and endurance training leads to an improvement of exercise capacity and respiratory muscle endurance performance and reduces dynamic hyperinflation and breathlessness during exercise.

The results of this study may enhance the understanding of the mechanisms leading to improved exercise capacity when using IMT. Further studies are needed to verify the potential role of IMT during exercise rehabilitation programs in COPD patients.

\section{Disclosure}

The authors report no conflicts of interest in this work. This study has been registered at ClinicalTrials.gov (NCT00469313).

\section{References}

1. O'Donnell DE, Bertley JC, Chau LK, Webb KA. Qualitative aspects of exertional breathlessness in chronic airflow limitation: pathophysiologic mechanisms. Am J Respir Crit Care Med. 1997;155(1):109-115.

2. Nici L, Donner C, Wouters E, et al; ATS/ERS Pulmonary Rehabilitation Writing Committee. American Thoracic Society/European Respiratory Society statement on pulmonary rehabilitation. Am J Respir Crit Care Med. 2006;173(12):1390-1413.

3. Wanke T, Formanek D, Lahrmann H, et al. Effects of combined inspiratory muscle and cycle ergometer training on exercise performance in patients with COPD. Eur Respir J. 1994;7(12):2205-2211.

4. [No authors listed]. Standardization of Spirometry, 1994 Update. American Thoracic Society. Am J Respir Crit Care Med. 1995;152(3): 1107-1136.

5. ATS ACCP statement on cardiopulmonary exercise testing. Am J Res Crit Care Med. 2003;166:111-116.

6. Stubbing DG, Pengelly LD, Morse JL, Jones NL. Pulmonary mechanics during exercise in normal males. JAppl Physiol. 1980;49(3): 506-510.

7. Borg GA. Psychophysical bases of perceived exertion. Med Sci Sports Exerc. 1982;14(5):377-381.

8. O' Donnell DE, Lam M, Webb KA. Measurement of symptoms, lung hyperinflation, and endurance during exercise in chronic obstructive pulmonary disease. Am J Respir Crit Care Med. 1998;158(5 Pt 1): 1557-1565.

9. Koessler W, Wanke T, Winkler G, et al. 2 Years' experience with inspiratory muscle training in patients with neuromuscular disorders. Chest. 2001;120(3):765-769.

10. R Development Core Team. R: A Language and Environment for Statistical Computing. Vienna: R Foundation for Statistical Computing; 2010.

11. Gosselink R, Troosters T, Decramer M. Peripheral muscle weakness contributes to exercise limitation in COPD. Am J Resp Crit Care Med. 1996;153(3):976-980.

12. Polkey M, Kyroussis D, Hamnegard CH, Mills GH, Green M, Moxham J. Diaphragm strength in chronic obstructive pulmonary disease. Am J Respir Crit Care Med. 1996;154(5):1310-1317.

13. Covey MK, Larson JL, Wirtz SE, et al. High-intensity inspiratory muscle training in patients with COPD and severely reduced function. J Cardiopulm Rehabil. 2001;21(4):231-240. 
14. Lötters F, van Tol B, Kwakkel G, Gosselink R. Effects of controlled inspiratory muscle training in patients with COPD: a meta-analysis. Eur Respir J. 2002;20(3):570-577.

15. Larson JL, Kim MJ, Sharp JT, Larson DA. Inspiratory muscle training with a pressure threshold breathing device in patients with chronic obstructive pulmonary disease. Am Rev Respir Dis. 1988;138(3):689-696.

16. Polkey M, Moxham J. Attacking the disease spiral in chronic obstructive pulmonary disease. Clin Med. 2006;6(2):190-196.

17. van Noord JA, Aumann JL, Janssens E, et al. Effects of tiotropium with and without formoterol on airflow obstruction and resting hyperinflation in patients with COPD. Chest. 2006;129(3):509-517.

18. Maltais F, Hamilton A, Marciniuk D, et al. Improvements in symptomlimited exercise performance over $8 \mathrm{~h}$ with once-daily tiotropium in patients with COPD. Chest. 2005;128(3):1168-1178.

19. Somfay A, Porszasz J, Lee SM, Casaburi R. Dose-response effect of oxygen on hyperinflation and exercise endurance in nonhypoxaemic COPD patients. Eur Respir J. 2001;18(1):77-84.

20. Palange P, Vali G, Onorati P, et al. Effect of heliox on lung dynamic hyperinflation, dyspnea, and exercise endurance capacity in COPD patients. J Appl Physiol. 2004;97(5):1637-1642.

21. Eves ND, Petersen SR, Haykowsky MJ, Wong EY, Jones RL. Heliumhyperoxia, exercise, and respiratory mechanics in chronic obstructive pulmonary disease. Am J Respir Crit Care Med. 2006;174(7): $763-771$.
22. Martinez FJ, de Oca MM, Whyte RI, Stetz J, Gay SE, Celli BR. Lung-volume reduction improves dyspnea, dynamic hyperinflation, and respiratory muscle function. Am J Respir Crit Care Med. 1997;155(6):1984-1190.

23. O’Brien GM, Furukawa S, Kuzma AM, Cordova F, Criner GJ. Improvements in lung function, exercise, and quality of life in hypercapnic COPD patients after lung volume reduction surgery. Chest. 1999;115(1):75-84.

24. Porszasz J, Emtner M, Goto S, Somfay A, Whipp BJ, Casaburi R. Exercise training decreases ventilatory requirements and exerciseinduced hyperinflation at submaximal intensities in patients with COPD. Chest. 2005;128(4):2025-2034.

25. Casanova C, Cote C, de Torres JP, et al. Inspiratory-to-total lung capacity ratio predicted mortality in patients with chronic obstructive pulmonary disease. Am J Respir Crit Care Med. 2005;171(6):591-597.

26. Ramirez-Sarmiento A, Orozco-Levi M, Guell R, et al. Inspiratory muscle training in patients with chronic obstructive pulmonary disease: structural adaptation and physiologic outcomes. Am J Respir Crit Care Med. 2002;166(11):1491-1497.

27. Villafranca C, Borzone G, Leiva A, Lisboa C. Effect of inspiratory muscle training with an intermediate load on inspiratory power output in COPD. Eur Respir J. 1998;11(1):28-33.
International Journal of COPD

\section{Publish your work in this journal}

The International Journal of COPD is an international, peer-reviewed journal of therapeutics and pharmacology focusing on concise rapid reporting of clinical studies and reviews in COPD. Special focus is given to the pathophysiological processes underlying the disease, intervention programs, patient focused education, and self management protocols.

\section{Dovepress}

This journal is indexed on PubMed Central, MedLine and CAS. The manuscript management system is completely online and includes a very quick and fair peer-review system, which is all easy to use. Visit http://www.dovepress.com/testimonials.php to read real quotes from published authors. 